Case Report

\title{
Idiopathic Thrombocytopenic Purpura in Patients with Ischaemic Heart Disease - A Therapeutic Challenge
}

\author{
AKM Monwarul Islam ${ }^{1}$,TanveerAhmed² ${ }^{2}$ Ishrat Jahan Shimu ${ }^{3}$, Samsun Nahar $^{4}$, Mohammad Arifur Rahman ${ }^{5}$, Afzalur Rahman $^{6}$
}

\begin{abstract}
:
Idiopathic thrombocytopenic purpura (ITP) and myocardial infarction (MI) in an individual patient is a rare combination. MI mandates thrombolytic and antiplatelet therapy which increases the risk of bleeding in ITP. So far, no guideline deals with
\end{abstract}

management protocol for ischaemic heart disease (IHD) in ITP patients. Here, we describe 2 cases of IHD who developed ITP while on antiplatelet therapy.

Key Words: Idiopathic Thrombocytopenic Purpura, Coronary Artery Disease, Thrombocytopenia.
Introduction:

Idiopathic thrombocytopenia purpura (ITP), also called immune thrombocytopenic purpura,is an autoimmune disorder with a low platelet count and mucocutaneous bleeding. Autoantibody-mediated platelet destruction, as well as, impaired platelet production both contribute to the pathophysiology of ITP. Quantitative as well as qualitative deficiency in platelet function leads to a bleeding tendency. On the other hand, ITP tends to increase the risk of cardiovascular diseases (CVD) e.g., IHD, stroke, transient ischemic attack and heart failure. ${ }^{1}$ ITP may even lead to a prothrombotic state which may be related to endothelial damage caused by antigenic mimicry between platelets and

1. Associate Professor, Department of Cardiology, National Institute of Cardiovascular Diseases, Dhaka, Bangladesh.

2. Specialist, Department of Cardiology, United Hospital Ltd., Dhaka, Bangladesh.

3. Assistant Registrar, Department of Cardiology, National Institute of Cardiovascular Diseases, Dhaka, Bangladesh.

4. Specialist, Department of Cardiology, United Hospital Ltd., Dhaka, Bangladesh.

5. Junior Consultant, Department of Cardiology, National Institute of Cardiovascular Diseases, Dhaka, Bangladesh.

6. Afzalur Rahman, Director and Professor, National Institute of Cardiovascular Diseases, Dhaka, Bangladesh.

Address of Correspondence: Dr. AKM Monwarul Islam, Associate Professor, Department of Cardiology, National Institute of Cardiovascular Diseases, Dhaka, Bangladesh. Mobile: +8801712564487, Email:drmonwarbd@yahoo.com. endothelial cells ${ }^{2}$ or, related to administration of intravenous immunoglobulin (IVIG) for the treatment of ITP ${ }^{3}$.Occurrence of acute coronary syndrome ${ }^{4-6}$, deep vein thrombosis and pulmonary embolism ${ }^{7,8}$, and ischaemic stroke ${ }^{9-11}$ has been described in association with ITP. Thrombolytic and antiplatelet therapy, the integral part of standard management of these patients, certainly increases the risk of bleeding in the context of already compromised platelet function. So far, no consensus exists regarding the optimal revascularization strategy and antiplatelet treatment policy in patients with ACS or stable coronary artery disease who have simultaneous ITP. Here, we present 2 cases of old MI who developed ITP while on antiplatelet drugs.

\section{Case 1}

A 71-year-old hypertensive man was on aspirin along with standard treatment for stable coronary artery disease with the history of postero-infero-lateral MI 1 year back. He was allergic to clopidogrel. During routine follow up, his serial platelet counts were 115,000 and $45,000 / \mathrm{mm}^{3}$ over 4 weeks. However, he had no obvious bleeding manifestations, and there was no bony tenderness, lymphadenopathy or organomegaly. Also, he did not have fever recently and take any new drug. He was referred to a haematologist. Bone marrow examination was suggestive of ITP. Platelet count further dropped to $10,000 / \mathrm{mm}^{3}$, however, no obvious bleeding occurred. Aspirin was withheld for fear of bleeding,

DOI: http://dx.doi.org/10.3329/bhj.v33i1.37029

Copyright (c) 2017 Bangladesh Cardiac Society. Published by Bangladesh Cardiac Society. This is an Open Access articles published under the Creative Commons Attribution-NonCommercial 4.0 International License (CC BY-NC). This license permits use, distribution and reproduction in any medium, provided the original work is properly cited and is not used for commercial purposes. 
oral methyl prednisolone followed by azathioprine was given. Platelet count rose to $55,000 / \mathrm{mm}^{3}$ but the general condition of the patient deteriorated and he developed significant adverse effects characterized by mouth ulceration, glucose intolerance and hepatitis. Methyl prednisolone and azathioprine were stopped, the patient improved rapidly, and the platelet count remained between 30,000 and 60,000/ $\mathrm{mm}^{3}$. Aspirin was reintroduced with close clinical and haematological monitoring. The platelet count remained unchanged, no bleeding encountered, and the patient remained stable.

\section{Case 2}

A 65-year-old diabetic man with history of inferior MI was on clopidogrel along with other medications. He refused any invasive procedures. During routine follow up, his platelet count was $65,000 / \mathrm{mm}^{3}$, however, he did not have any bleeding manifestations. His hemoglobin was $12.6 \mathrm{~g} / \mathrm{dL}$, erythrocyte sedimentation rate (ESR) $20 \mathrm{~mm}$ in first hour, serum creatinine $1.03 \mathrm{mg} / \mathrm{dL}$, and SGPT 35 units/L. Bone marrow examination by a haematologist revealed features suggestive of ITP. Clopidogrel was continued while the patient was on close clinical and haematological monitoring. There was no bleeding manifestations, and he was doing well in 9-month follow up.

\section{Discussion:}

Simultaneous occurrence of IHD and ITP is rare because of the physiological role of platelets in coagulation. Nevertheless, acute MI has been reported in even severely thrombocytopenic patients. ${ }^{12}$ On the other hand, ITP developing in otherwise stable coronary artery disease (CAD)patients, as is the issue in the 2 cases presented here, has not been reported adequately. Presence of thrombocytopenia of ITP poses serious management problems in ACS, as well as, in stable CAD patients in which a good balance between the prevention of thrombosis and haemorrhagic risk demands.

Patients with acute ST-elevation MI and ITP have successfully been managed with thrombolytic therapy with limited experience. ${ }^{13}$ Coronary revascularization either by percutaneous coronary intervention $(\mathrm{PCI})$ or by coronary artery bypass graft (CABG) surgery seems to be safe and feasible, having a good early outcome and a low complication rate. ${ }^{14}$ Historically, CABG was preferred to $\mathrm{PCI}$ in ITP patients with CAD because majority of the coronary artery lesions can be dealt with in a more predictable way and antiplatelet therapy can be managed with greater flexibility with CABG in comparison to $\mathrm{PCl} .{ }^{15} \mathrm{In}$ fact, despite low platelet count, CABG has successfully been carried out with some increase in bleeding risk compared to $\mathrm{CABG}$ in the general population. ${ }^{16-9}$ On the other hand, available data suggest that $\mathrm{PCl}$, including primary $\mathrm{PCl}$, can be safe and feasible in carefully selected patients. ${ }^{16,}{ }^{20-6} \mathrm{Li}-\mathrm{Sh}$ e et al. reported a 75year-old patient with ITP who underwent 3 separate coronary interventions for recurrent ACS and in-stent restenosis, including $\mathrm{PCl}$ and cutting-balloon angioplasty and using unfractionated heparin, dual antiplatelet therapy and platelet transfusion. ${ }^{21}$ They also analyzed the reported 18 cases of ITP who underwent PCl between 1999 and 2013; preprocedural platelet count ranged from $3 \times 109 / L$ to $322 \times$ 109/L (mean $78.5 \pm 81.5 \times 109 / \mathrm{L}$ ). Glycoprotein Ilb/IIla inhibitors were administrated during $4 \mathrm{PCl}$ procedures, clopidogrel before and during $\mathrm{PCl}$ in 9, ticlopidine in 1, aspirin in 9 , and no antiplatelet drug before and during $\mathrm{PCl}$ in 5 . One instance (5.6\%) of major bleeding ${ }^{27}$ and 6 minor bleeding were observed. Ten patients (55.6\%) were discharged on double antiplatelet therapy, 3 on single antiplatelet drug, while 3 patients did not receive any antiplatelet agent. Performance of $\mathrm{PCl}$ in a patient with ITP requires sufficient inhibition of platelet function to prevent stent thrombosis, but not enough to cause bleeding. For this reason, most expert opinions recommended bare-metal stent (BMS) as opposed to drug-eluting stent (DES) to minimize the duration of dual antiplatelet therapy in case bleeding occurs. ${ }^{14}$ However, DES has also been implanted successfully. ${ }^{16}$ Platelet transfusion and IVIG have been used in some cases of ITP to reduce the risk of bleeding during coronary revascularization.IVIG may paradoxically induce thromboembolic events including myocardial infarction. ${ }^{28-}$ ${ }^{30}$ Since severe bleeding is uncommon when the platelet count is above $30,000 / \mathrm{mm}^{3}$, treatment is usually initiated when the count falls below $30,000 / \mathrm{mm}^{3}$. 31

Antiplatelet therapy in the setting of ITP and IHD should be used with great caution. Dual antiplatelet drugs e.g., combination of aspirin and clopidogrel, when indispensable, should be used generally only for short time, with special attention to the indication, platelet count, and bleeding risk. In both the cases presented here, mostly single antiplatelet drug was used, in the first case only aspirin because of suspected clopidogrel intolerance, and in the second case only clopidogrel because of gastrointestinal intolerance. Aspirincan be safely continued after $\mathrm{CABG}$ and $\mathrm{PCl}$ unless clinical bleeding occurs, or until the platelet count falls to $10,000-20,000 / \mathrm{mm}^{3}{ }^{32}$ This may probably be applicable to those otherwise stable CAD patients with ITP who did not have any revascularization strategy, as are the cases presented here.

Actually, in ITP, in contrast to the more common findings of petechiae and purpura, severe haemorrhage, such as intracranial haemorrhage, overt gastrointestinal bleeding, 
and haematuria, is uncommon. This was illustrated in a systematic review of prospective clinical studies, which included 5336 adults with ITP 33 ;the incidence of intracranial haemorrhagewas $1.4 \%$, while that of other severe bleeding was $9.6 \%$. In a population-based study that included 3771 patients with ITP, the risk of severe bleeding at disease onset was $<1 \% 34$. Predictors of severe bleeding include the degree of thrombocytopenia (from $<10,000$ to $<20,000 / \mathrm{mm}^{3}$ ), previous minor bleeding, and chronic ITP (i.e., diagnosis $>12$ months prior). ${ }^{33}$

\section{Take-home message:}

Combination of ITP and IHD including ACS, though rare, does occur. Presence of thrombocytopenia in ITP is not protective to ACS.

Despite increased risk of haemorrhage, major bleeding rarely occurs until platelet count falls below 20,000 to $10,000 / \mathrm{mm}^{3}$.

No established protocol exists for management of IHD in the setting of ITP, or ITP in case of chronic IHD. Treatment should be individualized.

Safety of thrombolytic therapy is limited by inadequate experience.

Growing evidence favours coronary revascularization including $\mathrm{PCl}$ and $\mathrm{CABG}$.

BMS may be preferable to DES. Periprocedural anticoagulants and antiplatelets may be used, certainly with careful monitoring. Platelet transfusion is rarely needed.

For maintenance therapy, single antiplatelet drug, preferably aspirin, canusually be safely given or continued as long as platelet count is approximately more than $30,000 / \mathrm{mm}^{3}$, or there is evidence of bleeding.

Antiplatelet drugs should be withdrawn when platelet count falls below $10,000 / \mathrm{mm}^{3}$, or there is active major bleeding, and treatment should probably be started to raise platelet count.

\section{Reference:}

1. Chandan JS, Thomas T, Lee S, Marshall T, Willis B, Nirantharakumar K, et al. The association between idiopathic thrombocytopenic purpura and cardiovascular disease: a retrospective cohort study. J ThrombHaemost. 2018 Mar;16(3):474-80.

2. Fruchter O, Blich M, Jacob G. Fatal acute myocardial infarction during severe thrombocytopenia in a patient with idiopathic thrombocytopenic purpura. Am J Med Sci. 2002;323(5):279-80.

3. Hefer D, Jaloudi M. Thromboembolic events as an emerging adverse effect during high-dose intravenous immunoglobulin therapy in elderly patients: a case report and discussion of the relevant literature. Ann Hematol. 2005;84(6):411-5.

4. Fernández-Fernández FJ. Acute coronary syndrome in patients with thrombocytopenia. Rev EspCardiol (Engl Ed). 2017 Aug;70(8):682.

5. Shah AH, Anderson RA, Khan AR, Kinnaird TD. Management of immune thrombocytic purpura and acute coronary syndrome: A double-edged sword! Hellenic J Cardiol. 2016 Aug 20. pii: S11099666(16)30151-8. (5)

6. Shen F, Nfor T, Bajwa T. Recurrent acute myocardial infarction in patients with immune thrombocytopenic purpura. J Patient Cent Res Rev. 2014;1:41-5.

7. Emre JC, Önalan T, Soyer N, Deniz S, Özhan MH. Coinciding of pulmonary embolism and immune thrombocytopenia; A rare case. Respir Case Rep. 2016; 5(2): 93-6.

8. Kim SK, Kang JY, Choi SH, Hong YA, Kim JS, Kim $\mathrm{SW}$, et al. A case of pulmonary thromboembolism in a patient with idiopathic thrombocytopenic purpura. Korean J Med. 2011 Aug;81(2):251-6. Korean.

9. Park HK, Lee SH. Ischemic stroke associated with immune thrombocytopenia: lesion patterns and characteristics. Neurol Sci. 2014 Nov;35(11):1801-6.

10. De La Peña A, Fareed J, Thethi I, Morales-Vidal S, Schneck MJ, Shafer D. Ischemic stroke in the setting of chronic immune thrombocytopenia in an elderly patient-a therapeutic dilemma. Clin Appl Thromb Hemost. 2012 Jun;18(3):324-6.

11. Mahawish K, Pocock N, Mangarai S, Sharma A. Cerebral infarction in idiopathic thrombocytopenic purpura: a case report. BMJ Case Rep. 2009;2009. pii: bcr04.2009.1748.

12. Caputo RP, Abraham S, Churchill D. Transradial coronary stent placement in a patient with severe idiopathic autoimmune thrombocytopenic purpura. $J$ Invasive Cardiol. 2000;12:365-8.

13. Koklu E, Kus G, Yuksel IO, Kucukseymen S, Arslan S. Successful thrombolytic therapy for ST-elevation acute myocardial infarction in a patient with immune thrombocytopenic purpura. Am J Emerg Med. 2016 Feb;34(2):345.e1-3.

14. Russo A, Cannizzo M, Ghetti G, Barbaresi E, Filippini E, Specchia S, et al. Idiopathic thrombocytopenic purpura and coronary artery disease: comparison between coronary artery bypass grafting and 
percutaneous coronary intervention. Interact CardiovascThorac Surg. 2011 Aug;13(2):153-7.

15. Yellin A, Refaely Y, Paley M, Simansky D. Major bleeding complicating deep sternal infection after cardiac surgery. J ThoracCardiovasc Surg. 2003 Mar;125(3):554-8.

16. Lee $\mathrm{CH}$, Kim U. Revascularization for patients with idiopathic thrombocytopenic purpura and coronary artery disease. Korean Circ J. 2014 Jul;44(4):264-7.

17. Jubelirer SJ, Mousa L, Reddy U, Mir M, Welch CA. Coronary artery bypass grafting (CABG) in patients with immune thrombocytopenia (ITP): a community hospital experience and review of the literature. $W V$ Med J. 2011 Nov-Dec;107(6):10-4.

18. Rossi M, Lewis M, Hutchinson N. Coronary artery bypass grafting in idiopathic thrombocytopenia: use of thromboelastometry without platelet transfusion. Tex Heart Inst J. 2010;37(3):361-4.

19. Fatimi S, Kella DK, Muzaffar M, Hanif HM. On pump coronary surgical revascularization in a patient with chronic immune thrombocytopenic purpura. J Pak Med Assoc. 2010 Mar;60(3):239-40.

20. Fujino S, Niwa S, Fujioka K, Mabuchi T, Noji Y, Yamaguchi $\mathrm{M}$, et al. Primary percutaneous coronary intervention by a stentless technique for acute myocardial infarction with idiopathic thrombocytopenic purpura: A case report and review of the literature. Intern Med. 20 16;55(2):147-52.

21. Li-Sha G, Peng C, Yue-Chun L. Recurrent acute coronary syndrome and restenosis after percutaneous coronary intervention in a patient with idiopathic thrombocytopenic purpura: a case report and literature review. BMC CardiovascDisord. 2015 Sep 18;15:101.

22. Nurkalem Z, Isik T, Cinar T, Ergelen M. [Primary coronary intervention for acute ST-elevation myocardial infarction in a patient with immune thrombocytopenic purpura]. Turk Kardiyol Dern Ars. $2011 \mathrm{Jul} ; 39(5): 414-7$. [Article in Turkish]

23. Yildiz A, Coskun U, Batukan OE, Keskin K. Primary percutaneous coronary intervention for acute myocardial infarction in a young female with idiopathic thrombocytopenic purpura: a case report and review. Case Rep Med. 2010;2010:854682.

24. Neskovic AN, Stankovic I, Milicevic P, Aleksic A, Vlahovic-Stipac A, Calija B, et al. Primary PCl for acute myocardial infarction in a patient with idiopathic thrombocytopenic purpura. A case report and review of the literature. Herz. 2010 Jan;35(1):43-9.

25. Gracia MC, Cebollero IC, Lezcano JS, Osuna GG, Miguel JA, Peralta LP. Invasive treatment performed for acute myocardial infarction in a patient with immune thrombocytopenic purpura. Int J Cardiol. 2008 Jul 21;127(3):e183-5.

26. Kim JH, Park KU, Chun WJ, Kim SH, Nah DY. Primary percutaneous coronary intervention for acute myocardial infarction with idiopathic thrombocytopenic purpura: a case report. J Korean Med Sci. 2006 Apr;21(2):355-7.

27. Fuchi T, Kondo T, Sase K, Takahashi M. Primary percutaneous transluminal coronary angioplasty performed for acute myocardial infarction in a patient with idiopathic thrombocytopenic purpura. JpnCirc J. 1999;63:133-6.

28. Amit G, Yermiyahu T, Gilutz H, llia R, Zahger D. Thrombocytopenia, immunoglobulin treatment, and acute myocardial infarction - a case report. Angiology. 2005 Mar-Apr;56(2):229-31.

29. Torbey E, Yacoub H, McCord D, Lafferty J. Two cases and review of the literature: primary percutaneous angiography and antiplatelet management in patients with immune thrombocytopenic purpura. ISRN Hematol. 2013 Dec 29;2013:174659.

30. Zaid G, Dawod S, Rosenschein U. Immune thrombocytopenic purpura and myocardial infarction: a dilemma of management. Isr Med Assoc J. 2013 Dec;15(12):775-6.

31. Cines DB, Blanchette VS. Immune thrombocytopenic purpura. N Engl J Med. 2002 Mar 28;346(13):9951008. Review.

32. Faraday N. Pro: Should aspirin be continued after cardiac surgery in the setting of thrombocytopenia? J CardiothoracVascAnesth. 2006 Feb;20(1):112-3.

33. Neunert C, Noroozi N, Norman G, Buchanan GR, Goy J, Nazi I, et al. Severe bleeding events in adults and children with primary immune thrombocytopenia: a systematic review. J ThrombHaemost. 2015 Mar;13(3):457-64.

34. Moulis G, Palmaro A, Montastruc JL, Godeau B, Lapeyre-Mestre M, Sailler L. Epidemiology of incident immune thrombocytopenia: a nationwide populationbased study in France. Blood. 2014 Nov 20;124(22):3308-15. 